\title{
Necesidad de un registro de las colecciones audiovisuales y sonoras de América Latina
}

On behalf of a record of Latin American audio and audiovisual collections

\author{
Jorge CALDERA-SeRRANo \\ Facultad de Ciencias de la Documentación y la Comunicación, Universidad de Extremadura, \\ Plazuela de Ibn Mar-wan, s/n, 06071 Badajoz (España), jcalser@alcazaba.unex.es
}

\begin{abstract}
Resumen
Se define y analiza la necesidad de llevar a cabo un registro y valoración de las colecciones audiovisuales y sonoras en los diferentes países de la América Latina. Dicho registro debe ir más allá de la mera identificación de la colección, la cual a día de hoy sigue faltando, para proceder al análisis de sus contenidos y alcance, así como de de su estado de conservación documental. Este registro y análisis debe ser realizado por instituciones supranacionales que una vez llevado a cabo el estudio, promuevan la implantación de políticas de preservación encaminadas a garantizar el acceso y preservación de los contenidos sonoros y audiovisuales.
\end{abstract}

Palabras clave: Patrimonio documental. Información audiovisual. Información sonora. Registro de colecciones. América Latina.

\section{Introducción}

Lo público tiene la obligación de preservar su memoria, su historia, su tradición. Los organismos públicos ya sean estatales o transnacionales deben preservar el patrimonio documental de países desarrollados como de aquellos que están en desarrollo. La pérdida por decisión o dejación del patrimonio se traduce en la pérdida del ADN de los pueblos, donde se recogen las decisiones, los errores, los héroes y villanos, su folclore, su tradición, la forma de vida de las personas, de cómo nos hemos relacionado con la naturaleza y como hemos vivido en sociedad, en definitiva, todo aquello que nos ha convertido en lo que ahora somos y, seguramente, lo que seremos en el futuro.

El Patrimonio debe conservarse desde un amplio punto de vista y un amplio espectro de materiales. Igualmente relevante es la conservación del Patrimonio Documental, memoria escrita sobre soporte físico de nuestros ancestros.

En el marco de dicho Patrimonio Documental parece urgente la intervención sobre el material audiovisual y sonoro, los cuales por sus condiciones intrínsecas químicas están en peores condiciones de preservación y conservación que

\begin{abstract}
The need to catalogue and evaluate the audiovisual and sound collections in Latin America is discussed. Such a catalogue should go beyond the mere identification of the collections, which today is still missing, and include the analysis of their contents and scope, as well as an assessment of their preservation state. This project should be carried out by supranational institutions that, thereafter, should promote the implementation of preservation policies aimed at ensuring that the Latin American audiovisual and audio heritage is properly preserved and accessed.
\end{abstract}

Keywords: Audiovisual heritage. Audiovisual information. Sound records. Cataloguing. Latin America.

otros muchos soportes documentales con mayor antigüedad.

La Unesco, ya en el año 1980, llamada la atención sobre la necesidad de preservar las colecciones audiovisuales y sonoras, ya que su estado de conservación era en muchos casos deficientes y alertaba que durante los próximos veinte años (desde el prisma del año 1980) se podrían perder gran cantidad de materiales derivados de las malas condiciones físicas y químicas de conservación de estas colecciones.

Han pasado no sólo el periodo de veinte años de alarma propuesto por la Unesco, sino que prácticamente se ha duplicado, y en muchos casos no se han llevado a cabo políticas ni actuaciones para poder solucionar dicha problemática.

Son muchas las colecciones audiovisuales y sonoras, especialmente las ubicadas en medios de comunicación, que en un momento determinado de su historia han comenzado a trabajar en formato digital (Caldera y Arranz, 2012), y por lo tanto a preservar dichas colecciones en estos nuevos formatos, pero el problema sigue siendo la preservación de los contenidos analógicos, los cuáles no han sido volcados en sopor- 
tes digitales, con unas condiciones de preservación no siempre óptimas, y con graves problemas de acceso a los contenidos derivados de la mala preservación y de la falta de reproductores.

Son variadas las zonas del mundo que están en alerta de preservación. Zonas del mundo donde las instituciones públicas $-\mathrm{y}$ en muchos casos privadas - cuentan con prioridades mucho más importantes que la preservación documental, como es la subsistencia física del pueblo. Latinoamérica es una zona muy amplia del planeta, con países con trayectoria y tradición dispares, por lo que es complicado el simplificar un diagnóstico general sobre el estado de la preservación de las colecciones audiovisuales y sonoras.

No obstante, desde estas páginas se intenta plasmar la necesidad de una intervención rápida para determinar el estado de la cuestión de la preservación de las colecciones audiovisuales y la generación de sinergias y políticas supranacionales válidas para poder intervenir de forma urgente para salvaguardar, de forma colaborativa y solidaria, las colecciones audiovisuales y sonoras de Latino América.

Existen instituciones supranacionales como Unasur (Serbin, 2009), con la colaboración de Unesco, o viceversa, las que deberían abanderar la preservación documental y garantizar la Memoria de cada uno de los Países y también de prácticamente un continente que realmente tienen muchos puntos de unión.

\section{Lo audiovisual y lo sonoro}

Nuestro entorno, nuestro medio ambiente, nuestra forma de aprender y nuestros modelos de enseñar, nuestro ocio y entretenimiento, nuestra forma de acceso a la información, nuestra forma de comunicarnos se ha transformado en las últimas décadas. Todo es cada vez más audiovisual, seguramente no tanto sonoro, pero sí audiovisual. Nos atrevemos a aseverar que la forma en la que se nos recordará dentro de dos siglos será más por nuestros registros audiovisuales que por nuestro material textual. Lo audiovisual lo está desbancando todo, a otros métodos de difusión, a otros métodos de escritura, a otros métodos de asimilación. Lo audiovisual está presente en las múltiples pantallas que nos rodean, en las pantallas por medio de las cuáles los "nativos digitales" reconocidos e identificados por Prensky (2010) acceden a su entorno. Pantallas de ordenador, de celular, de videojuego, de televisión, de cine, de los múltiples aparatos digitales que se desperdigan por nuestros hogares.
La importancia de las colecciones audiovisuales va más allá de los medios de comunicación, de la televisión y de la radio. Son otras muchas las instituciones que en sus gabinetes de comunicación han generado y generan gran cantidad de material que deberá tenerse presente si se quiere preserva la Memoria Audiovisual y Sonora de un país, pueblo o región.

Son muchos los autores que han publicado trabajos teorizando sobre documentación audiovisual (Hidalgo, 2013; Caldera y Arranz, 2012; López de Quintana, 2014; Giménez, 2012; Póveda, Caldera y Polo, 2010); menos sobre documentación sonora en los medios (Cebrián, 1994; Nuño, 2007; Rodríguez, 2001). Algunos incluso los que comienzan a analizar este fenómeno sobre la base del desarrollo tecnológico y la automatización de los procesos (Caldera, 2014; Caldera y Sánchez, 2008; Pérez, Sánchez y Caldera, 2004), aunque la realidad nos demuestra que deben realizarse esfuerzos y estudios previos para determinar el estado de conservación y poder llevar a cabo un registro de las colecciones, igualmente para reconocer los requerimientos y necesidades de destrezas y habilidades por parte de los profesionales, que aún a día de hoy no están claramente explicitados. Tal y como se señalaba, existen colecciones audiovisuales y sonoras que se deben comenzar a trabajar desde abajo, determinando sus características básicas y, en definitiva, estudiando cómo se conserva, qué se custodia y cuál es realmente el valor patrimonial, documental, histórico, etc., que tiene dicho material.

Las colecciones audiovisuales están actualmente mejor conservadas y atendidas, aunque no crean que se encuentran salvadas. La obsolescencia, desde la tecnológica a la programada, hace inevitable el estudio y análisis urgente de los soportes para poder salvaguardar el material audiovisual y sonoro por medio de la digitalización, de políticas de digitalización a escala mundial. Por su parte, el abandono y dejadez de las colecciones sonoras es bastante superior a los de las colecciones audiovisuales. De ahí que sea realmente importante el conocer cuáles son las principales colecciones atendiendo a sus contenidos y especificidades, para así plasmar en políticas públicas líneas de mejora y de actuación para preservar este importante Patrimonio Mundial.

\section{Instituciones fundamentales en el proceso}

En un trabajo previo (actualmente en fase de revisión) se apostaba claramente por la creación de un Instituto de lo Audiovisual y lo Sonoro 
para toda América Latina, con el fin de que dicha institución fuera la encargada de custodiar los principales contenidos, salvaguardándolo por medio de un cuidada digitalización. Sin lugar a dudas, esto nos parece un camino correcto que debieran seguir el conjunto de instituciones públicas nacionales en colaboración con las principales agencias supranacionales de la región. Ahora bien, independientemente de esta labor, los países deben ser los responsables de salvaguardar las colecciones nacionales, solicitando para ello ayuda, asesoramiento, etc., pero llevando a cabo las labores necesarias para su preservación.

Una vez que se tenga muy claro que son las agencias, ministerios, instituciones competentes en cada uno de los países los que deben marcar las pautas, metodologías y líneas de actuación para la preservación de las colecciones audiovisuales locales, se estima que dicha labor debe ser realizada de manera conjunta con instituciones supranacionales, entre las cuales destacan Unesco, Unasur y la Organización de Estados Americanos.

La Unesco es especialmente importante por su alcance y por sus programas "Memorias del Mundo" (Edmondson, 2002) en el que se encuentra integrado, en cierta manera, el de "Archivos audiovisuales" (Edmondson, 2004) (Unesco, 2015), que no solo incluye a los de naturaleza audiovisual sino también sonora. La Unesco es especialmente sensible en la lucha de la salvaguarda de información en estos soportes, además de ser conocedor de los problemas derivados de los soportes documentales y de la necesaria preservación en condiciones estables de temperatura y humedad. De ahí, que estimemos que igual que la Unesco debe abanderar la creación de un instituto supranacional para la preservación de los principales acervos culturales de los diferentes países de América Latina, también debiera realizar una labor previa de investigación, registro e identificación de las colecciones audiovisuales de la región. La sede principal de este organismos para temas científicos se encuentra ubicada en la ciudad de Montevideo, por lo que sería un buen lugar para ubicar un instituto de preservación absolutamente digital, que fuera también el responsable de realizar el registro.

No obstante, y además de la Unesco, parece fundamental la colaboración para la realización del registro de colecciones audiovisuales de entidades supranacionales que agrupen y aglutinen intereses comunes presentes en todos los países de la región. Simplemente, queremos destacar la importante colaboración de organismos como la Organización de Estados Ame- ricanos o Unasur. Las cambios estratégicos y las alineaciones de países otorgan a Unasur un rol cada vez más importante en la región. Unasur, con sede en la ciudad de Quito (Ecuador) está organizando de manera decidida los intereses de los diferentes países de la región, además de sumar socios estratégicos más allá de los límites físicos de América del Sur (orientación inicial y principal de la Unión). De ahí, que la colaboración de Unasur sea importante y prioritaria en la puesta en marcha de cualquier línea de actuación que se quiera sea efectiva y global para la región.

\section{Metodología del registro de lo sonoro y lo audiovisual}

Es importante determinar el cómo y quién debe llevar a cabo el registro. Llevar a cabo un registro a priori de todas las colecciones sonoras y audiovisuales de toda la América Latina es sin lugar a dudas un trabajo que debe ser organizado y coordinado por las diferentes instituciones mencionadas con anterioridad: Unesco, UNASUR y el ministerio competente de cada país. Sobre todo es relevante el poder ponderar cuáles son las principales colecciones, qué información es la más relevante dentro de la colección y cuál de ellas corre un grave peligro de perderse de forma definitiva y, por lo tanto, debe ser de las primeras en ser intervenidas. Como puede apreciarse, lo que se requiere y desea no es un mero registro de la existencia de la colección, sino que va mucho más allá, analizando condiciones de conservación, accesibilidad en cierta manera y contenidos, tanto genéricos como específicos.

El objetivo a lograr es el llevar a cabo el registro de las colecciones Audiovisuales y Sonoras de América Latina, ya sean de carácter público como privado, determinando los principales contenidos y condiciones de preservación e integridad documental de la información, con el fin de identificar y conocer las colecciones y sus contenidos y detectar las anomalías que pudieran deteriorarlas.

El porqué de dicha labor es identificar las principales colecciones, contenidos y estados de conservación, para garantizar la preservación y el acceso a los mismos, tanto por parte de los investigadores y comunicólogos como de la sociedad en general.

Aunque el análisis y registro de cada una de estas colecciones es local, el registro, y por ende todo el proyecto, cuenta con una visión integral y de carácter regional. No es nuestro propósito el análisis de una colección, sino la necesidad de llevar a cabo un proyecto para 
valorar las colecciones de los diferentes países, independientemente de la concienciación en materia de preservación con la que se cuente en cada uno de los países. De ahí que tratemos este proyecto como un elemento vertebrador y de unión de países, ya que cuenta con un principio de solidaridad entre naciones de la región, que se traduce en la implementación del programa por medio de una institución tan importante como es la Unesco, con relación, e incluso financiación, de Unasur y de la Organización de Estados Americanos. Este plan de trabajo debe de entenderse como un proyecto global, que debe implicar a todos los países de la región y que es un paso previo para trabajos y proyectos más ambiciosos.

En un trabajo previo, tal y como se ha indicado previamente, se analiza la necesidad de crear organismos supranacionales para la preservación de los recursos audiovisuales y sonoros, que se encuentran en estos momento en graves problemas de preservación y de integridad documental, digitalizando los recursos más interesantes tanto a nivel local como de América Latino, pero no desarrollando una migración masiva de los recursos audiovisuales y sonoros, siendo ésta otra fase posterior que deberán ir desarrollando los países involucrados.

Pero sin lugar a dudas, previo a crear dicho instituto, es obligatorio el conocer en qué momento nos encontramos, cómo están nuestras colecciones, cómo de deteriorado y olvidado tenemos nuestro patrimonio documental sonoro y audiovisual.

Las colecciones que deben ser analizadas serán de todo tipo. A priori no puede determinarse cuáles serán más ricas y potentes en recursos audiovisuales y sonoros, por lo que será en cada país donde habrá que determinar las principales colecciones, primero para ponderar la importancia de las mismas y así organizar las visitas a las colecciones, después para valorar cuáles son aquellas que deben contar con la primera intervención para conservar o para digitalizar sus recursos.

Se puede estimar que inicialmente las colecciones más destacadas de la región serán las cadenas de televisión en el caso de las colecciones audiovisuales, y las emisoras de radio para las colecciones sonoras. Eso nos dice la lógica y seguramente así sea en muchos casos, no obstante se tendrá que analizar la existencia y antigüedad de productoras de radio y televisión, colecciones de instituciones tanto públicas como privadas, colecciones personales o familiares de titularidad privada, fundaciones, gabinetes de comunicación de empresas, obras sociales o museos de instituciones bancarias, etc. La casuística es enorme y será en cada uno de los países donde se habrá de realizar un importante trabajo de campo para poder así determinar las principales colecciones de la zona.

La elaboración de dichos listados de colecciones, previa incluso a las visitas, no puede ser realizada por personal externo al propio país, por lo que en todo momento se debe hablar de colaboración y trabajo interdisciplinar. Incidimos en la necesidad de llevar a cabo una clara colaboración con instituciones públicas, universidades, asociaciones profesionales, historiadores, ministerios y personalidades del mundo del audiovisual, televisivo y radiofónico para conocer cuáles son las diferentes colecciones y su importancia. El contar con investigadores locales se nos muestra fundamental ya que serán ellos los que puedan aportar información oportuna sobre las colecciones audiovisuales y sonoras del país. Además, se pueden utilizar las estructuras estables y contactos de instituciones como la Unesco que tienen presencia en la mayor parte de los países. Su registro del ámbito cultural tanto de colecciones como de personas relevantes puede ser un primer paso fundamental para no entrar "a ciegas" en cada uno de los países de América Latina.

Esta labor debe ser llevada a cabo por un equipo de investigación multidisciplinar, el cual debe estar integrados por perfiles tan variados como gestores de proyectos, gestores de información, historiadores, conservadores y comunicólogos. Equipos que deben ser planteados de forma eficiente en su número y organización, con una estructura ágil que facilite tanto los contactos con las administraciones locales como con organismos gubernamentales y supranacionales.

Debe quedar claro que a esta primera fase de registro se le deberá dotar de transparencia y publicidad, de tal manera que el registro obtenido pueda ser accesible para la comunidad científica y también para la sociedad en general, en definitiva, que aquellas colecciones a las cuales nos acerquemos para su análisis entiendan que la labor realizada no intenta interrumpir su labor sino dar a conocer la existencia de la colección. El trasvase o migración de la información de estas colecciones no será parte de este primer momento, por lo que la parte legal no será un requerimiento fundamental al ser un mero registro y breve descripción del contenido general. Cuestión aparte es que, aprovechando la confección del registro, los especialistas puedan analizar de forma rápida el estado de preservación e importancia de las colecciones analizadas. 
Los elementos con los que deberá contar dicho registro deben organizarse entorno a los siguientes cinco epígrafes:

(a) Titularidad. Se debe aportar la información respecto a quién cuenta con los derechos sobre la colección. Se habrá de identificar tanto si es persona física como jurídica, así como los mecanismos oportunos para contactar con dicha institución o persona física. Además, se señalará y registrará la existencia de información en la red sobre dicha colección además de las condiciones ajustadas a derecho en las que se encuentra la colección. Por lo tanto, se habrá de identificar claramente si dicho archivo es de titularidad pública o privada, y en ambos casos se determinarán los contactos y los derechos de acceso.

(b) Cronología. Un elemento fundamental es determinar entre qué fechas se cuenta con información en dichos depósitos. Desde el material más antiguo al más moderno, investigando y detectando posibles vacíos temporales o continuidad en la captación y registro de los contenidos. Esta información deberá ser aportada por el personal encargado de la gestión y custodia de la colección, ya que de lo contrario sería imposible conocer dicha información salvo que fuese analizado de forma pormenorizada, lo que, en este fase de registro, es absolutamente inviable. Determinar las fechas de comienzo de las imágenes nos va a aportar con claridad la importancia de la colección, atendiendo a los periodos que cubre.

(c) Contenidos. Junto con lo anterior, es fundamental el determinar el alcance del contenido, definiendo su valor. Conocer si es una colección general o especializada, cuáles son las imágenes o hitos más relevantes que, a priori, se encuentran en el depósito, ayudará claramente a conocer la valía de los contenidos del depósito; $\mathrm{y}$, por lo tanto, nos ayudará a priorizar en caso de ser necesaria la intervención en diferentes colecciones. Saber qué personajes se conservan y en qué momentos históricos será fundamental para determinar el potencial, ya sea de material público o privado. Si fuere posible sería interesante cuantificar los contenidos, señalando por ejemplo el número total de horas por series y colecciones en el marco de la colección matriz.

(d) Soportes. Identificar cuáles son los soportes con los que cuentan facilita información de la cronología que cubre la colección. Además, es relevante determinar los tipos de soportes y contenido asociados a cada uno de ellos. Se ha de reconocer que existen soportes, por sus condiciones innatas físico-químicas, que ya se encuentran en grave estado de preservación, por lo que podrá aportarnos señales claras de alarma (Saavedra, 2011).

(e) Conservación y diagnóstico: Tras el análisis de contenidos, fechas y soportes, será relevante el determinar cómo se encuentran los soportes documentales desde el punto de vista de la degradación y la conservación. El uso, el mal uso, las condiciones físicas de las instalación, la manipulación, etc., son algunos de los elementos que pueden deteriorar tanto el material sonoro como el audiovisual, por lo que habrá que intentar determinar en el momento exacto del registro cómo se encuentran estos soportes. Evidentemente es imposible el realizar un estudio minucioso, pero sí que se puede realizar una cata aleatoria entre las estanterías para determinar cómo se encuentran los soportes. Igualmente relevante es conocer las instalaciones así como las potenciales medidas de seguridad con las que se cuenta para posibles contingencias. Analizar el depósito, condiciones de temperatura, humedad relativa, limpieza, manipulación, control de plagas, etc., podrá tranquilizarnos, o alarmarnos, sobre los peligros a los que está expuesto el depósito que alberga a la colección sonora y/o audiovisual.

A grandes rasgos, estos serían los elementos que se deberían registrar. Posteriormente esta información en sí misma ya es realmente útil y válida para los investigadores, que podrán así conocer cuáles son las colecciones existentes y las temáticas que en ellas se tratan, destacando momentos y personajes visualizados o escuchados en los soportes. Pero volvemos a señalar que no debería quedar dicho registro en una mera enumeración de colecciones, sino en una herramienta fundamental para la intervención y mejora de la preservación documental de las colecciones sonoras y audiovisuales.

\section{Conclusiones}

La creación de un registro de las colecciones audiovisuales y sonoras de América Latina no es sino el primer paso de otras muchas actuaciones más ambiciosas. Los registros realizados con anterioridad sobre estas colecciones han quedado obsoletos por el tiempo en el que se realizaron y, especialmente son incompletos, ya que el análisis confeccionado sobre esta región no fue ni mucho menos exhaustivo, como sí pasó en los países anglosajones y en la mayor parte de los países europeos.

Por lo tanto parece oportuna la realización de esta primera actuación con el fin de delimitar la realidad, actuando posteriormente en consecuencia a partir de los datos obtenidos. 
Hacer un registro ayudará a mostrar los síntomas, realizar un claro diagnóstico y plantear las actuaciones locales y regionales necesarias para la preservación de las colecciones.

Colecciones sonoras y audiovisuales que deberán ser identificadas desde un punto de vista amplio y ambicioso, en el cual queden integradas las colecciones privadas y públicas, de diferentes instituciones y de personas físicas, para lo cual serán necesario los contactos con investigadores locales para identificar estas colecciones que posteriormente serán registradas.

Un registro que no sólo debe quedarse en la mera identificación, sino que deberá contar con una valoración del alcance e importancia de los contenidos, así como detectar las condiciones de preservación y de conservación; en definitiva, definir el riesgo de pérdida de contenidos y la necesidad de la intervención.

Por lo tanto, registrar para conocer, identificar para definir, y ponderar para determinar el grado de deterioro e importancia de intervención respecto a otras colecciones.

No debemos de olvidar que el Patrimonio y la Memoria Sonora y Audiovisual no sólo pertenece a aquellas personas que lo generan, ni a aquella institución de la cual emanan, sino que ese material es la Memoria en movimiento de un pueblo, país y/o región, y que por lo tanto debe ser garantizado su acceso a las generaciones futuras, para que desde su análisis, investigación y conocimiento, se pueda mejorar el futuro de los pueblos en conjunto y de las personas que lo conforman.

\section{Reconocimiento}

Este trabajo ha sido financiado por el Gobierno de Extremadura (Consejería de Educación, Ciencia y Tecnología) y el Fondo Social Europeo dentro del plan de apoyo a las actuaciones de los Grupos de Investigación inscritos en el catálogo de la Junta de Extremadura. GR10019.

\section{Referencias}

Caldera-Serrano, J. (2014). Realidad aumentada en televisión y propuesta de aplicación en los sistemas de gestión documental. // El Profesional de la Información. 23:6, 643-650

Caldera-Serrano, J.; Arranz-Escacha, P. (2012). Documentación audiovisual en televisión. Barcelona: EPI/UOC.

Caldera-Serrano, J.; Sánchez-Jiménez,R (2008). Ontología para el control y recuperación de información onomásti- ca en televisión. // El Profesional de la Información. 17:1, 86-91.

Cebrían Herreros, Mariano (1994). Información radiofónica: mediación técnica, tratamiento y programación. Madrid: Síntesis.

Edmondson, Ray (2002). Memoria del mundo: directrices para la salvaguardia del patrimonio documental. París: Unesco.

Edmonson, Ray (2004). Filosofía y principios de los archivos audiovisuales. París: Unesco http://unesdoc.unesco.org/ images/0013/001364/136477s.pdf (10-03-2015).

Giménez-Rayo, Mabel (2012). La documentación audiovisual en televisión en el mundo 2.0: retos y oportunidades. // Trípodos. 31 (2012) 79-97. http://tripodos.com/ index.php/Facultat_Comunicacio_Blanquerna/article/do wnload/39/24 (10-01-2015).

Hidalgo Goyanes, Paloma (2013). Patrimonio audiovisual en televisión. // Marcos Recio, Juan Carlos (coords.). Gestión del patrimonio audiovisual en medios de comunicación. Colección Ciencias de la información. Comunicación audiovisual; 18. Madrid: Síntesis, 2013. 53-82.

López-de-Quintana, Eugenio (2014). Rasgos y trayectorias de la documentación audiovisual: logros, retos y quimeras. // El profesional de la información. 23:1 (enerofebrero 2014) 5-12. http://elprofesionaldelainformacion .com/contenidos/2014/enero/01.pdf (10-03-2015).

Nuño Moral, María Victoria (2007). Documentación en el medio radiofónico: hacia un entorno digital. Madrid: Síntesis.

Perez-Agüera,J.R.; Sánchez-Jiménez, R.; Caldera-Serrano, J. (2004). Adaptación de tecnologías stream y XML a centros de documentación en televisión. Revista Española de documentación Científica. 27:4, 441-454

Póveda-López, I.C.; Caldera-Serrano, J.; Polo-Carrión, J.A. (2010). Definición del objeto de trabajo y conceptualización de los sistemas de información audiovisual de la televisión. Investigación Bibliotecológica. 24:50, 15-34

Prensky, Mark (2010). Nativos e inmigrantes digitales. // Cuadernos SEK 2.0, 1-20. http://www.marcprensky.com /writing/Prensky-NATIVOS\%20E\%20INMIGRANTES\% 20DIGITALES\%20\%28SEK\%29.pdf

Rodríguez Reséndiz, Perla Olivia (2011). Modelo de desarrollo de la Fonoteca Nacional de México. Madrid: Universidad Complutense. 302 p. ISBN 978-84-695-0764-3.

Saavedra Bendito, Pau (2011). Los documentos audiovisuales: Qué son y cómo se tratan. Gijón: Trea, 176 p. ISBN 9788497045889.

Serbín, Andrés (2009). América del Sur en un mundo multipolar: ¿es la Unasur la alternativa?. // Nueva Sociedad:219, 145-156. http://www.nuso.org/upload/articulos/ 3588_1.pdf (10-03-2015).

UNESCO. Archivo audiovisuales. http://www.unesco.org/ news/es/comunication-and-information-acesss-toknowlede/archives/audiovisual-archives/ (10-03-2015).

UNESCO (1980). Actas de la Conferencia General, 21 ${ }^{\mathrm{a}}$ reunión Belgrado, 23 de septiembre - 28 de octubre de 1980: Volumen 1: Resoluciones http://unesdoc.unesco. org/images/0011/001140/114029s.pdf\#page=163 03-2015).

Enviado: 2016-07-28. Segunda versión: 2013-0Aceptado: 2013-0- 